\title{
Submission Letters across English Language Teaching and Mathematics: The Case of Iranian Professionals
}

\author{
Alireza Jalilifar \\ Department of English Language and Literature \\ Shahid Chamran University of Ahvaz, Molavi Square, Ahvaz, Iran \\ Tel: 98-611-333-5005 Ext. $287 \quad$ E-mail: jalilifar20@yahoo.com
}

\begin{abstract}
Submitting an article to an English journal for publication requires enclosing an accompanying cover letter. Yet, the phraseology and rhetorical conventions of such letters are not comprehensively documented in literature. This article investigates two English corpora of genuine electronic submission letters to journal editors by Iranian English Language Teaching and Mathematics professionals. After gathering 200 e-mail correspondences of academics with journal editors worldwide, 60 messages (30 from each) sent with the purposes of providing or requesting information were selected and analyzed for specific rhetorical patterns following Santos' (2002) model. Eventually, the results were juxtaposed to a highly characteristic covering letter - provided in Okamura and Shaw (2000). With few exceptions in Math corpus, both corpora illustrate proper choices regarding phraseology. Concerning rhetoric, ELT submission emails are more compatible with those of English native academics, whereas Math messages carry the rhetorical patterns in Non-native academics' messages. With the diversity that may exist in the generic structure and function of submission letters, further research investigating communicative purposes of e-mail genre is needed.
\end{abstract}

Keywords: Genre analysis, Cross-disciplinary analysis, Cover letters, Rhetorical conventions, Phraseology

\section{Introduction}

Since the early 80s applied linguists and language teachers, especially those concerned with the teaching of English for Specific Purposes (ESP) and English for Academic Purposes (EAP), have shown a great deal of interest in genre-based approaches to the analysis of written and spoken discourse. This interest has, to a large extent, been motivated by pedagogical concerns, in particular by the need to provide satisfactory models and descriptions of academic and scientific texts and to enhance the ability of non-native speakers to understand, and where appropriate, to produce such texts in a rhetorically effective manner.

The textual repertoire within academic English has not only broadened but taken on a more social dimension, a central concern with real audiences and purposes. The advent of electronic spaces promises to broaden and diversify this repertoire even further. In addition, potential audiences for electronic texts are larger, more culturally diverse, and more unpredictable than ever before. However, academic research has not caught up with its task of sufficiently defining the norms which govern the use of this new medium, and it has so far provided no clear answer to the question of whether a stylistic protocol exists for the writing of e-mail messages. One example of these messages is electronic letters-to-the-editors.

The advent of the Internet and the electronic mail has profoundly changed the process of sending and receiving messages. Submitting an English article to a scientific journal requires enclosing an electronic cover letter accompanying the article to the journal. Yet, the possible phraseology and rhetorical conventions of such letters-to-editors are inadequately documented in the academic research arena. This is perhaps because the letter has almost no impact on the research or reviewing process. The neglect might also stem from the fact that it is only recently that an electronic submission letter has become a popular medium of communication among researchers and journal editors, and in fact, many journals still accept submission to be carried out only via air mail. This may lead to the conception that an electronic submission letter and an old non-electronic one should not be different, and so researchers might simply draw a blank on the potential impact of the medium on the structure of the electronic submission letter. However, writing an electronic submission letter is an international concern as more and more writers attempt to find space for publication in world reputed journals. On the other hand, with the increasing number of electronic journals and their time-honored tendency to accept submission via email, the need for writing an electronic submission letter is felt ever more. Within the ESP movement, more recently, this has drawn the attention to the rhetorical and schematic analysis of what Swales (1990) refers to as occluded genres to meet the communication demands of the academic community and to reflect the individual agency of those who use them.

Many journals provide a form for the submitting author to fill, which eliminates the need for a self-generated cover letter. Alternatively, for some authors, no more than one very generic sentence is necessary as an accompaniment to the 
submission. According to Gump (2004), a well designed and succinct covering letter can "establish the author's credibility", request for consideration and possible publication of one's unsolicited manuscript, and communicate a close affinity with editor (pp. 92-93). Donovan (2004), acknowledging Gump's components of a covering letter, suggests the prospective authors provide the names of three potential reviewers, with their email and postal addresses (p. 222). In addition to being neat and error-free, Gump (2004) suggests using "credibility-establishing letterhead" (p. 95) and signing the letter if a covering letter is posted. Gump advises prospective authors to be concise, be authoritative but kind, and promise to consider the editor's suggestions for revision (p. 97). Gump's suggestion on covering letters, though appealing and potentially valuable, has unfortunately not been empirically tested.

In the domain of submission letters- an example of occluded genre- not many studies have so far been done. Swales (1996) examined a particular category of very short transactional letters, the submission letters-to-editors, written by native and non-native speakers of English (NSEs and NNSEs respectively). Okamura and Shaw (2000) scrutinized letters of article submission by native and non-native academics and compared them with efforts to write such letters by native and non-native speaker non-professionals from the perspective of rhetoric and phraseology. Magnet and Carnet (2006) investigated discursive and linguistic features of the letters-to-editors. Crossley (2007) analyzed article submission letters trying to identify the systematic variation in performance between L1 and L2 writers of English based on the linguistic features used to denote spatio-temporal perspectives.

Results have shown that non-native speakers are more prone to use the letter to emphasize their professional status and to intensify their request for attention by requesting for a response soon or as soon as possible (Swales, 1996). Results have also revealed that the teaching approach for writing depends significantly "on the status of the learners, and lexical phrases are particularly important for non-natives" (Okamura \& Shaw, 2000, p. 1), that the cover letters provided by L2 writers generally adhered to the standards of the genre membership (Crossley, 2007), and that with their discursive features, "letters-to-the-editors can be considered a genre, but not a stable genre, since it has evolved since its origin" (Magnet \& Carnet, 2006, p. 179).

Research concerning the cross-disciplinary analysis of the schematic structure of emails sent to professional journals for the purpose of article submission-something with which the present study is concerned- is at its embryonic stages. The problem is how we see this type of email developing in future as an informative covering letter, logically constructed, can indicate that the manuscript is also well-written and suitable for publication (Donovan, 2004; Gump, 2004). Baron (1998) believes that the future linguistic shape of email will be determined by interaction between two factors: technological potential and social choice. He compares the language of email messages to a spoken pidgin arguing that when the range of functions and the number of users expand, the email system evolves into a more linguistically rich and stable creole. Though this idea sounds a bit far-fetched now, what is apparent is that email is becoming as ubiquitous as the telephone in terms of ease and access. So, there is a rapid growth of correspondence through email and an urgent need to study cross-disciplinary variations. Moreover, research regarding the rhetoric and phraseology required for submission letters-to-editors (there is almost no guidance available in the textbooks, especially for non-natives of English who wish to write in this genre in a communicatively efficient manner), as well as the important pedagogical rationale for extending this genre is tremendously limited. Thus, the present research, following the generic model of business letters of negotiation proposed by Santos (2002), analyzed two corpora of English email messages sent by Iranian English Language Teaching (ELT) and Mathematics academics to journal editors worldwide with the communicative purposes of providing and requesting information.

In this article, Iranian English ELT and Mathematics' submission letters-to-editors to the international journals were initially analyzed to see the extent that the emails differ from one another as far as the schematic moves (Note 1), conversational features, lexico-grammatical features, as well as positive and negative politeness strategies (Note 2) are concerned. The features focused on, among other possible features, could provide sufficient evidence on the nature of covering letters at different levels of analysis. Specifically,

1) Is there any significant difference between submission letters written by ELT and math professionals on the move types, steps, and sub-steps utilized by each group?

2) Does any significant difference exist in the lexico-grammatical, textual, and conversational features in ELT and math submission letters?

3) To what extent are the ELT and math submission letters different in terms of negative and positive politeness strategies that they utilize?

4) In the next phase of the study, the researcher measured the degree that the English emails written by both ELT and math professionals reflect the standards for genre membership by comparing the results of the study with a canonical (conventional) native English letter of submission. More specifically, the study targeted seeking answers to the following question: 
5) To what extent do the submission letters written by the Iranian academics-both ELT and math academics- reflect the rhetorical standards for genre membership?

\section{Methodology}

\subsection{Participants}

The subjects in this research are among the Iranian ELT and math professionals who intend to submit an article to an international journal. The rationale for the selection of the fields was two-fold:

1. In the hierarchy of basic sciences math has a top-list location, and any decision made regarding generic analysis of math emails may provide possible hypotheses for the move structure of emails from other fields.

2. Selecting ELT from social sciences has partly to do with the fact that non-native ELT professionals are more proficient than Math professionals in using emails, and the emails they write can be more representative of standard rhetorical structure in the context of Iranian professionals writing emails in English.

The target group of Iranian academic writers from Math and English departments across the country was contacted. Sample letters of submission were collected from departments of Mathematics and English in Tehran, Mashhad, Shiraz, Isfahan, Ahvaz, Kerman, Systan-Baluchestan, Yazd, Guilan, and Tabriz. These professionals were asked to send to the researcher some of their genuine submission letters to international scientific journals for a generic analysis while a promise was made to keep the content of their letters confidential. Both groups have one thing in common and it is their membership in the international sub-culture of science while they differ in what is considered as their proficiency and meta-linguistic awareness as far as communicating through English is concerned. First, for both groups Persian is the local mother tongue and English the international language through which both are expected to push their submissions ahead. It goes without saying that, for ELT professionals, English is the subject of study as opposed to Math professionals for whom the subject is Mathematics while English is the channel for communication of information. Accordingly, ELT professionals are expected to feel considerably at ease communicating with the journal editors while Math professionals with less competence in English may find their way through by asking for counseling from other professionals or utilizing the non-electronic sample letters available in books.

\subsection{Corpus}

First, 200 e-mail messages were gathered from the correspondence of Iranian English and Mathematics professionals with journal editors worldwide (100 from each discipline). Different sources were used to obtain the e-mails. They were mostly received as a result of 350 emails sent by the researcher to English and Mathematics professionals in faculties and departments.

The first round of analysis was performed on the initial corpora to acquire a general impression of the content as well as the organization of each messages, and also to choose homogeneous data as far as the communicative purpose was concerned, i.e. to select only those letters-to-editors sent for the purpose of article submission. Hereby, emails to editors for other purposes were omitted. Eventually, 60 covering letters (30 from each group) sent by 60 different English and Mathematics professionals (EPs and MPs hereafter) were selected for a deeper analysis. Even though there might be intervention on the part of translators or revisers in shaping the covering letters, they were ultimately regarded as the product of the researchers themselves because controlling this variable was practically not possible as emails had already been written by the time they were forwarded to me. The principal reason for the selection of these two types of messages was the fairly high frequency of these functions in e-mail messages in general and in the current corpora in particular.

For the purposes of recognition and easier access, the emails of each group were tagged separately. The symbols employed were E-em (1-30) and M-em (1-30) for English and Mathematics email messages by professionals respectively. Subsequently, on the basis of Santos' (2002) framework, the electronic messages were carefully investigated, and the obligatory and optional moves as well as the steps and sub-steps realizing the moves were identified. Also, the elements through which negative and positive politeness strategies are manifested were identified and operationally defined. Then, the frequency of each parallel move, step, sub-step, textual and conversational feature, and negative and positive politeness strategies was tallied.

In order to find whether the differences between the parallel moves, steps, sub-steps (Table 3), lexico-grammatical features (Table 4) and politeness strategies (See Table 10) in the two corpora were significant, a chi square test was applied, assuming (.05) level of significance.

\section{Insert Table 1 here}

\subsection{Models of analysis}

Scrutinizing several coding schemes (Barron, 2006; Bhatia,1993; Connor \& Mauranen,1999; Flowerdew \& Dudley Evans, 2002; Flowerdew \& Wan, 2006; Henry \& Roseberry, 2001; Santos, 2002; Swales, 1990; Vergaro, 2002, 
2004), the present research employed the move schemata suggested by Santos (2002) for letters of negotiation exchanged for the purposes of providing or requesting information because it was the most comprehensive. Subsequently, using the linguistic system of politeness strategies adopted by Upton and Connor (2001) in their study concerning job application letters, I further explored possible national sub-cultural similarities and differences in the e-mail messages. The typical features of form and function in the two corpora were specified on the basis of Santos' (2002) model. Those elements which were present in the model and in the emails as well, and the elements which existed in the model but absent in the data were identified. In addition, if an element was encountered that was absent in Santos' model, that element was recognized and added to the model. Furthermore, if some elements in the Santos' model were absent in the data, they were recognized and deleted. Finally, providing some modification to Santos' (2002) model, the researchers came up with a provisional coding scheme for letters of article submission presented in Table 3.

\section{Data analysis}

\subsection{The parallel constitutive moves}

The results of chi-square tests for the constitutive moves indicated significant differences only in the distribution of the Establishing the territory move across EP and MP e-mail messages. Also, with the exception of Establishing the territory and Evaluating moves which were not frequent in either corpus, the remaining moves were obligatory. (See Table 1)

\section{Insert Table 1 right here}

\subsection{The parallel steps and sub-steps}

The chi-square test displayed significant differences in Indicating job status at university, Providing contact information, Providing author(s)' names, Indicating file format and Indicating journal name. However, the differences in the frequencies of the remaining steps and sub-steps were not statistically significant. Those steps and sub-steps with a frequency of occurrence of 15 or above were considered obligatory and the remaining ones optional. Table 2 presents chi square results for the constitutive moves and Table 3 suggests a provisional coding scheme for submission letters.

\section{Insert Table 2 right here}

\section{Insert Table 3 right here}

\subsection{The parallel lexico-grammatical features}

\subsubsection{Verbs}

To determine the patterns of tense variation across the two corpora, the most typical verbs used in the e-mail messages were listed in a five-category table. The categories under which verbs were classified consisted of: 1) present (also present perfect and present progressive); 2) past (also past perfect and past progressive); 3) passive (including stative); 4) active; and 5) modals. The results revealed significant differences in the use of Present tense, Active voice, and Modals while for Past tense and Passive voice the differences were -though frequent in the case of passive voice- not significant. Table 4 displays the results of tense and voice types.

\section{Insert Table 4 right here}

\subsubsection{Personal pronouns}

The categories under which personal pronouns were classified consisted of: 1) first-person singular; 2) second-person; 3) third-person singular; 4) first-person plural; 5) third-person plural; and 6) indefinite. The chi-square results revealed no significant difference in the use of $I$, You, It, and We. Additionally, 'third-person singular' except for It, third-person plural, and indefinite pronouns were totally absent in both corpora. (See Table 5)

\section{Insert Table 5 right here}

\subsection{The parallel textual features: Opening and closing steps}

Initially, the overall distribution of different forms realizing the opening as well as closing steps across EP and MP e-mail messages was studied and the frequency of each element was calculated. The chi-square results revealed significant differences only in the use of Dear + title + first name + surname for the opening step and (Best) (kind) regards and (Yours) sincerely for the ending step. Also, Dear + title + surname and Dear + title + first name + surname were the most frequent opening forms in EPs and MPs corpora respectively while EPs and MPs were more likely to use frequently the complimentary phrases (Best) (kind) regards and (Yours) sincerely for closing respectively. Tables 6 and 7 illustrate the results for opening and closing steps. (Explanation of the significance appears in the Discussion section)

\section{Insert Table 6 right here}

Insert Table 7 right here 


\subsection{The parallel conversational features}

Following Gimenez's (2000 \& 2006) conversational framework, four conversational features (discourse particles, abbreviation, contracted forms, and decapitalization) were studied. The results of chi-square tests, revealed significant differences only in the use of decapitalization. The results, also, indicated that EPs were more likely to utilize Decapitalization while MPs used Standard Abbreviation more frequently (See Tables 8 \& 9)

\section{Insert Table 8 right here \\ Insert Table 9 right here}

\subsection{The comparison of negative and positive politeness strategies}

The chi-square results revealed no statistically significant differences between the distributions of Indirectness strategy. Nevertheless, the obtained results of the chi-square test revealed a significant difference across the elements of Expressing indebtedness, use of formulaic expressions, and modals. (See Table 10 \& 11)

\section{Insert Table 10 right here}

Insert Table 11 right here

Concerning positive strategies, the chi-square results revealed no significant differences in the parallel distributions of Please + action verbs and Directness across the two corpora. (See Table 12)

\section{Insert Table 12 right here}

\section{Discussion}

The results revealed that, in the face of some minor differences, the overall schematic structure in the two corpora was much alike. The observed differences were partially associated to the effects of context on text, for example, disciplinary variability and the specific need requirements of each group. The differences were also along the lines of what Vassileva (2001) refers to as the intertextuality that somehow encompasses the concept of transfer from thematically related texts.

The findings indicate six functional moves across the two corpora, among which Establishing the information exchange chain, Providing information or answers, Requesting for information, action or favors, and closing were fully present in every email across the two corpora hence obligatory. The Establishing the territory and Evaluating moves which were present in some but not in all emails were regarded as optional.

The optionality of the establishing the territory and evaluating moves in both corpora might be related to the effect of the context on texts hence discipline-dependent. The evaluating move was more frequent in EP electronic messages, owing to the theoretical and more subjective nature of their field. For this group giving personal opinion or making comment were some of the ways to make more contribution to their email correspondence while MPs favored the Establishing the territory move in an attempt to set the scene and trigger the addressee's relevant schemata.

The comparison between EP and MP e-mail messages at the level of steps and sub-steps revealed interesting results. Variation according to discipline was highly significant with reference to the step, Indicating job status at university which frequently occurred in EP messages, and the steps Initial thanking, Final thanking, and Providing contact information, which were more frequent in the MP e-mail messages. With regard to the sub-steps, Providing author(s)' names, Indicating file format and Indicating journal name were more frequent in MP messages while significantly less frequent - even absent in some cases- in EP messages.

The higher frequency of the Indicating job status at university step in EP messages might be attributed to their higher awareness of the medium due to their higher level of English language proficiency and thus having easier access to e-mail guidelines available in the internet (One may simply try writing guidelines for cover letter or submission letter-to-editor in the search space of Google) as well as in the textbooks. Obviously, one reason for MPs' desire to do without this step in particular and write shorter e-mail messages in general may be the phenomenon of avoidance as a result of their lower level of language proficiency (Note 3). A more plausible justification for their economy in this step may be discoursal, cultural, and of course lack of rhetorical awareness.

Furthermore, the narrow set of realizations of the steps and sub-steps which occurred more repeatedly in MP messages can be explained by the intertextuality (Vassileva, 2001). As Vassileva points out, the production and reception of a given text is dependent upon the participants' knowledge of other texts. Vassileva also argues that not every new text is totally autonomous but draws at least on other previous texts. Accordingly, MPs seem to write electronic messages by observing certain cognitive schemata of previously written texts (traditional pen and paper letters in this case) and preserving the well- established non-electronic norms and conventions of these letters, for example initiating and terminating their messages with complimentary formulaic expressions. 
Concerning the second research question, the results of verb types/voice analysis showed that present tense and active voice were more recurrent than other categories in the two corpora; moreover, passive voice was also used very frequently in the two corpora though not as frequently as active voice. Oftentimes, the researcher has not prepared the covering letter in advance and has to produce it off the cuff. On such occasions, present and active voice is resorted to. Alternatively, the use of present tense may be due to the shared and expected ongoing correspondence which may be followed in later follow-up emails, so more a function of the requirement of the rhetorical act, not to mention the fact that present tense makes the sentence stronger and gives force to the writing.

Also, the frequent use of passive voice might be attributed to the content of the message. In fact, since the writers were simply explaining a case by introducing it rather than by expressing their personal opinion, the case (the article being submitted) appeared to be as significant as the idea itself.

Additionally, one might attribute the prevalence of modals in MP e-mail messages to their dependence on the conventions of traditional letters and hence their reliance on formulaic expressions for presenting a polite request. In this case, there was a functional shift as the modals did not echo standard meaning any longer.

Concerning the distribution patterns of personal pronouns, the higher frequency of first-person singular in EP and second-person in MP might imply disciplinary variability. EPs had a tendency to use a collocation of $I$ with private verbs expressing personal opinion-though not so frequently- (e.g., I think, I believe, etc.) to either indicate their wishes or plans or express their personal opinion and most frequently to request for action and favor (I would be very grateful if...). Since the medium is not necessarily connecting large groups of people in a discourse community together -as it is simply used by an academic trying to submit an article to a journal- the degree to which first person plural is used in both corpora is so small except for the cases in which the article has been co-authored; however, such cases do not necessarily entail the use of we. In addition, the more frequent use of you in MP electronic messages might be attributed to the higher frequency of the positive politeness strategy (i.e., directness) in the introducing or providing information move (Attached, you can find...). The overall findings are in consonance with Kuo's (1999) statement that such strategic use of personal pronouns seems to help writers to know how to emphasize their contribution to their fields, and how to seek cooperation and stress solidarity with expected interlocutors and their disciplines. In line with Hyland (2004), that "perceptions of audience in different genres influence rhetorical choices", it is argued here that cross-disciplinary differences as well as awareness of linguistic rules being constrained by contextual factors within the same genre also shape "patterns of engagement" (p. 22).

One prominent textual feature was the varied nature of the opening and ending steps across the two corpora. The results were contrary to those of Gains's (1998) reporting a high frequency of messages with no opening but a smaller number of messages with no ending step since almost all messages in the two corpora initiated or ended with some kind of opening or ending encoding politeness as indicating closer relationships. Additionally, the broad range of realizations for these steps may be justified by the flexibility inherent in this genre, thus allowing more personal idiosyncrasies to emerge. From these styles Dear + title + surname and Dear + title + first name + surname and Dear + sir/madam and Dear editor, which were more frequent in both corpora compared with other styles of opening presented, exposed the power of the genre which seems to require ceremonial type of opening. These styles may also be regarded as more polite which are more likely a combination of a Persian strategy and a power relationship between the gatekeepers and submitters. (Yours) sincerely and (Best) (Kind) Regards that were favored by both groups also appeared as optional conventions by discourse community members for ending e-mail messages.

Regarding conversational features, the infrequent use of discourse particles, non-standard abbreviations, contracted forms and the higher frequency of standard abbreviation in both corpora might be the formality required by the register of submission as far as submitting of an article is concerned. In essence, in such a register there is no place for more relaxed, unplanned, and conversational style and, quite the reverse, some degree of formality is expected. However, the more frequent use of decapitalization and non-standard abbreviations by EPs revealed the semi-formal and personalized nature of their style. These are undoubtedly features borrowed from other informal emails, but the question is whether the medium (informal email) outweighs the power relations in these letters. Also, the less frequent use of contracted forms in both corpora and carefree punctuations such as dehyphenated and decapitalized words in EP corpora provided evidence of the stylistic diversity immanent in electronic mails of information exchange genre, in this study the genre of submission letters. Accordingly, the results of this study, to some extent, suggested that the group less dependent on the conventions of traditional letters (EPs) was more aware of the medium with a higher level of language proficiency.

In general, the low occurrence of conversational features in both EP and MP e-mail messages was compatible with Gain's (1998) findings indicating that most of the e-mails in his data appeared to have a largely consistent style and were characterized as using "semi-formal tone of co-operative colleagues"(p. 86), fully formed and correctly punctuated. Such uniformity of written style in EP messages is a challenge to the general compromise among researchers that electronic messages are a mixture of both oral and written properties of language. In effect, the results of this study 
reveal that electronic submission letters are not inevitably informal or speech-like. As Biesenbach-Lucas and Weasenforth (2001, p. 136) argue, email writing is based on spoken as well as written language, and it is the outcome of a particular context of situation, i.e., audience factors, topic factors, and setting factors, which decide on oral or written features in any discourse. Consequently, the findings indicate that electronic messages exhibit a distinct medium of communication in their own right affected and shaped by syntagmatic structure, features of genre, and addressor/addressee relationship.

The observed difference in the negative politeness strategies in the two corpora (See Table 11) is probably proficiency-dependent which is associated with discipline here. The use of indirectness in both corpora and higher use of formulaic expressions, expressing indebtedness and modals by MPs may mark their reflection on the norms and conventions of previously learned traditional letters. In essence, MPs, using negative politeness strategy though unconsciously rather than being aware of their addressees, integrate the above strategies in their messages. Conversely, EPs integrate their positive and negative politeness strategies into more varied and individualized messages. This might be related to their higher English language proficiency, as mentioned before, and their linguistic flexibility while adopting a dignified and polite style all at once. It might also have to do with context of situation in general and awareness of audiences' expectations in particular. The results of this part may comply with Swales' (1996) generic study of covering letters where native speaker professionals were more inclined to use negative politeness strategies compared with non-native speaker professionals who were more inclined to use the letter to emphasize their professional status, and to persist on their request for attention by asking for a quick response hence using a positive politeness strategy. Results therefore provide sound evidence that EPs, despite their greater language proficiency, still exhibit marked differences with native speakers since their greater use of positive strategies suggests the influence of their first language culture on their second language performance.

Addressing the fourth question and taking both groups as professionals who already have membership to the same subculture, here international subculture of science, the researcher contrasted the results of the study with the generic structure of a canonical native letter of submission to the editor of an international journal. The letter was recognized as the most characteristic and frequent covering letter of article submission as mentioned in Okamura and Shaw (2000). Also the researcher took account of the way native speaker professionals (NSPs) followed through in the study, conducted by Okamura and Shaw (2000), of transactional letters. Initially, both groups - ELT and Math professionals were inclined to use the head acts almost as much frequently as NSPs did in Okamura and Shaw's (2000) study. In essence, the steps Introducing and providing information and Requesting for actions which are taken as head acts were, with minor differences, almost equally frequent in both ELT and Mathematics corpora which paves the way, though not full-scale, to justify the group membership in the genre. Secondly, as far as supportive moves in Okamura and Shaw's study are concerned, both ELT and Math professionals incorporated almost equally but scantily frequent steps with very marginal differences in which case they conformed to NSPs model in which only head acts are most dominant.

Regarding sub-steps, particularly the sub-steps Providing author(s)' names, Indicating file format and Indicating journal name, in essence, ELTs, not math professionals, were less likely to use such supportive moves, even though a move such as reference to file format might be very necessary in present-day communication but was not relevant to Okamura and Shaw's work where the covering letters all accompanied paper submission. This difference was partly compatible with Okamura and Shaw's study given that NSPs in their study scarcely contained supportive moves except for Request for the response and Comments on the paper. Actually, as Okamura and Shaw put it, NSPs rarely used supportive moves to explain the reason for writing or the status of the writer while professional non-natives (NNSPs) used a wide range of support moves. In actuality, professional non-natives were more prone to provide personal information about themselves or the source of their paper and to call attention to the value of the paper submitted "even flattering the editor- your world-famous journal" (p. 7), constructing much longer letters than the canonical one.

I might claim that, overall, understanding the rhetoric by both groups was probably the outcome of their sub-culture membership, here internationalized subculture of science. Furthermore, the reason for which Math professionals were more inclined to the use of supportive moves hence providing more details might be the concern of possible rejection from the part of journal editor under which they write the letters. This greater concern might suggest their less confidence in choosing the right linguistic and rhetorical patterns that might consequently lead to the editor's judgment of their lack of proficiency and effective writing.

Also, with regard to phraseology, except for very few cases in Mathematics corpus, both groups illustrated appropriate choice of vocabulary and phraseology, suggesting that for ELT professionals English is the subject of study on whose skills they have directly focused intensively hence helping them possess a high level of proficiency. For math professionals the reason is probably their acquaintance with the writing skill through attending to other genres and teaching in intertextuality. However, despite their successful performance in choice of vocabulary and phraseology, the deviations existing in the writings of MPs in textual features, use of formulaic expressions, expressing indebtedness, 
and modals raise doubt over the overall language proficiency of MPs. In a nutshell, the emails written by the Iranian professionals-both ELT and math academics- reflect the standards for genre membership to a great extent.

Taking up Santos' (2002) model as a framework, this study presented a provisional model of covering letters. Even though the proposed model may by and large be applicable to an extensive range of e-mail messages with the communicative purposes of requesting or providing information, there are probably conspicuous variations as far as schematic move structure, the choice of steps, and formal features across different disciplines are concerned. Therefore, email writers are expected to be aware of them, since conscious recognition of text structure is a requirement for their efficient reproduction.

Strengthening their mental schema by studying the proposed coding scheme and information in this research, professional email writers and readers can determine which parts of a message to skim first, and then decide whether to read, save, or delete the message without pinpointing the whole message. Additionally, acquiring specific schemata of e-mail sub-genres in different disciplines is needed since members of different discourse communities share various sets of specified schemata sticking to which is required to become active members of those discourse communities.

However, since the corpora analyzed are limited to 60 university professionals from only two disciplines, generalizations can only be made about letters-to-editors' emails by academic members of the disciplines under study, thus not allowing for a more comprehensive cross-cultural analysis of e-mail messages. Finally, this study, following Santos'(2002) framework, presents only the coding scheme of e-mail messages exchanged for the two communicative purposes of providing or requesting information, and thus it by no means encompasses the whole range of e-mail messages with other communicative purposes. With the diversity that exists in the academic community, the variety of disciplines involved, and the ever increasing need for submitting articles to scholarly journals, more interdisciplinary and intercultural studies are needed to make more valid generalizations. Further comparison of disciplinary sub-corpora will reveal something about the disciplines or language proficiency; comparison of the norms of email writing and the norms found empirically by previous writers for non-electronic submission letters will divulge the power of the medium; comparison of these emails with emails in general reveals the influence of social and power distance; and comparison of this study and the recommendations of experts might disclose weaknesses in these leters.

\section{References}

Baron, N. (1998). Letters by phone or speech by any other means: The linguistics of email. Language and Communication, 18 (2), 133-170.

Barron, A. (2006). Understanding spam: A macro-textual analysis. Journal of Pragmatics, 38 (6), 880-904.

Bhatia, V.K. (1993). Analyzing genre: Language use in professional settings. London: Longman.

Biesenbach-Lucas, S. \& Weasenforth, D. (2001). E-mail and word processing in the ESL classroom: How the medium affects the message. Language Learning \& Technology, 5 (1), 135-165.

Connor, U., \& Mauranen, A. (1999). Linguistic analysis of grant proposals: European Union research grants. English for Specific Purposes, 18 (1): 47-62.

Crossley, S. (2007). A chronotopic approach to genre analysis: An exploratory study. English for Specific Purposes, 26 (1): 4-24.

Donovan, S. K. (2004). Writing successful covering letters for unsolicited submissions to academic journals. Journal of Scholarly Publishing, 35 (3), 221-222.

Flowerdew, J., \& Dudley-Evans, T. (2002). Genre analysis of editorial letters to international journal contributors. Applied Linguistics, 23 (4), 463-489.

Flowerdew, J., \& Wan. A. (2006). Genre analysis of tax computation letters: How and why tax accountants write the way they do. English for Specific Purposes, 25 (2), 133-153.

Gains, J. (1998). Electronic mail-a new style of communication or just a new medium? An investigation into the text features of E-mail. English for Specific Purposes, 18 (1), 81-101.

Gimenez, J. C. (2000). Business e-mail communication: Some emerging tendencies in register. English for Specific Purposes, 19 (3), 237-251.

Gimenez, J. C. (2006). Embedded business emails: Meeting new demands in international business communication. English for Specific Purposes, 25 (2), 154-172.

Gump, S. E. (2004). Writing successful covering letters for unsolicited submissions to academic journals. Journal of Scholarly Publishing, 35 (2), 92-102.

Henry, A., \& Roseberry, R. L. (2001). A narrow-angled corpus analysis of moves and strategies of the genre: Letter of application. English for Specific Purposes, 20 (2), 153-167. 
Hyland, K. (2004). Patterns of engagement: Dialogic features and L2 undergraduate writing. In L. J. Ravelli \& R. A. Ellis (eds), Analysing academic writing: Contextualized frameworks (pp. 5-23). New York: Continuum.

Kuo, C. H. (1999). The use of personal pronouns: Role relationships in scientific journal articles. English for Specific Purposes Journal, 18 (2), 121-138.

Magnet, A., \& Carnet, D. (2006). Letters to the editor: Still vigorous after all these years. A presentation of the discursive and linguistic features of the genre. English for SpecificPpurposes, 25 (2), 173-199.

Okamura, A., \& Shaw, P. (2000). Lexical phrases, culture, and subculture in transactional letter writing. English for Specific Purposes, 19 (1), 1-15.

Santos, V.B.M. (2002). Genre analysis of business letters of negotiation. English for Specific Purposes, 21 (2), $167-199$.

Swales, J. M. (1990). Genre analysis: English in academic and research setting. Cambridge: Cambridge University Press.

Swales, J. M. (1996). Occluded genres in the academy: The case of the submission letter. In E. Ventola \& A. Mauranen (eds). Academic writing: Intercultural and textual issues (pp. 45-58). Amesterdam: John Benjamins.

Upton, T., \& Connor, U. (2001). Using computerized corpus analysis to investigate the text- linguistic discourse moves of a genre. English for Specific Purposes, 20 (4), 313-329.

Vassileva, I. (2001). Commitment and detachment in English and Bulgarian academic writing. English for Specific Purposes, 20 (1), 83-102.

Vergaro, C. (2002). “Dear Sirs, what would you do if you were in our position?', Discourse strategies in Italian and English money chasing letters. Journal of Pragmatics, 34 (9), 1211-1233.

Vergaro, C. (2004). Discourse strategies of Italian and English sales promotion letters. English for Specific Purposes, 23 (2), 181-207.

\section{Notes}

Note 1. For Swales. (1990). moves represent writer's social purposes.

Note 2. Politeness strategies are developed for the purpose of dealing with face threatening acts. Brown and Levinson. (1987). sum up politeness behavior in four strategies: (1) bold on record does nothing to minimize threats to hearer's face, (2) positive politeness strategy shows that you recognize that your hearer has a desire to be respected. It also confirms that the relationship is friendly and reciprocal, (3) negative politeness strategy recognizes the hearer's face and that you are imposing on him, and (4) off-record indirect strategy takes some of the pressure off you. You are trying to avoid direct face threatening acts of asking for something.

Note 3. MPs are regarded as less proficient on account of the fact that, for these academics, English is peripheral whereas EPs are usually more proficient because, for them, English is both the subject and the object of study.

Table 1. Frequency and Chi-square Results for the Constitutive Moves in the Two Corpora

\begin{tabular}{|c|c|c|c|c|}
\hline \multirow[t]{2}{*}{ Moves } & \multicolumn{2}{|c|}{ Frequency } & \multirow[t]{2}{*}{$\mathrm{x}^{2}$} & \multirow[t]{2}{*}{ P-value } \\
\hline & EP & MP & & \\
\hline Establishing the information exchange chain & 30 & 30 & .000 & 1.000 \\
\hline Establishing the territory & 1 & 8 & 5.444 & .020 \\
\hline Providing information or answers & 30 & 30 & .000 & 1.000 \\
\hline Requesting information, action or favors & 30 & 30 & .000 & 1.000 \\
\hline Evaluating & 5 & 0 & 2.667 & .102 \\
\hline Closing & 30 & 30 & .000 & 1.000 \\
\hline
\end{tabular}


Table 2. Frequency and Chi-square Results for Different Steps and Sub-steps across the Two Corpora

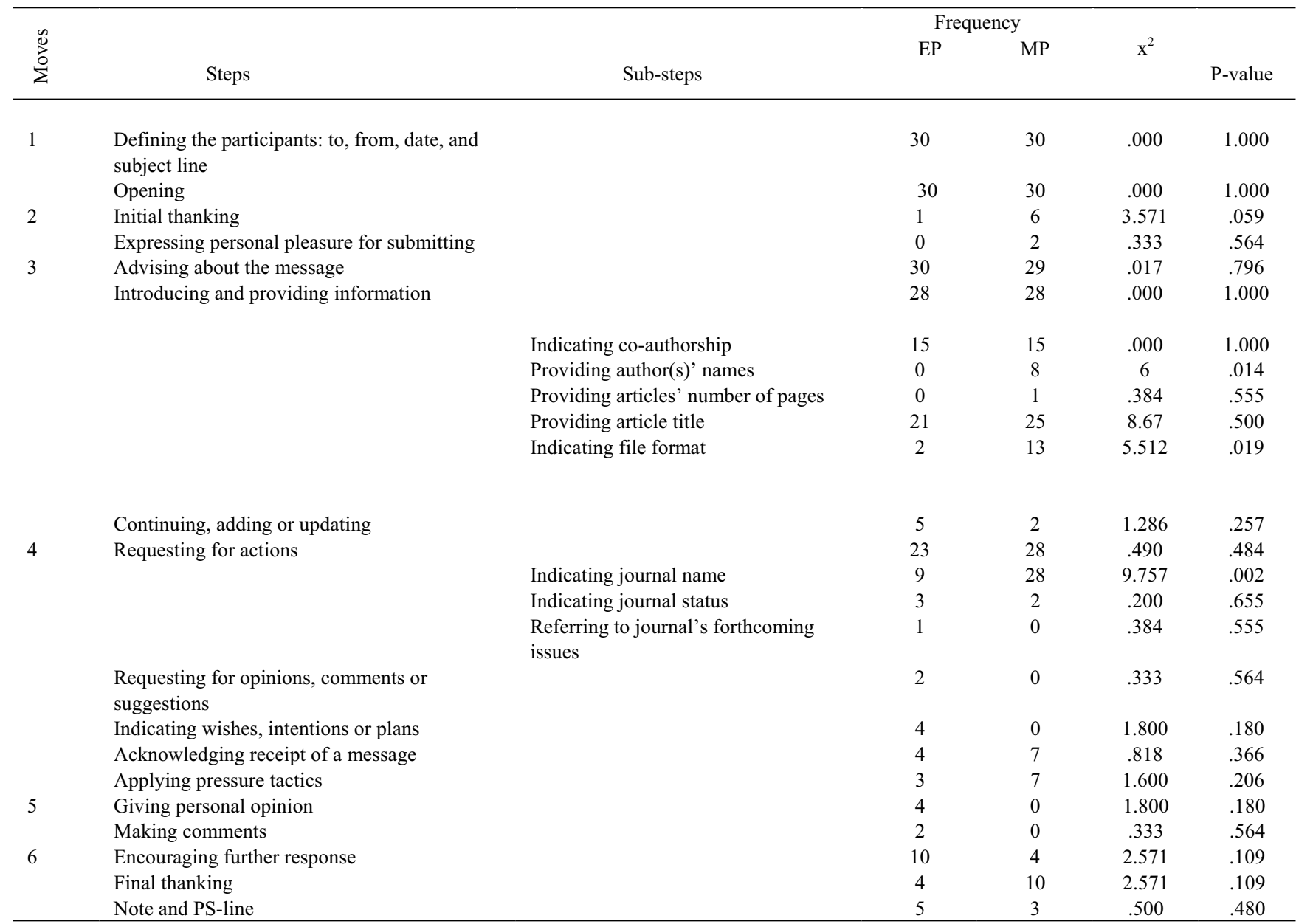

Table 3. Communicative Moves Characteristic of Letters of Article Submission

\begin{tabular}{|c|c|}
\hline Move & Definition and exemplification of moves \\
\hline $\begin{array}{lll}\begin{array}{l}\text { Establishing } \\
\text { exchange chain }\end{array} & \text { the information } \\
\end{array}$ & - the writer "introduces and sets the scene and the communication chain" (Santos, 2002, p. 178) \\
\hline a) Defining the participants & $\begin{array}{l}\text { - it incorporates four main elements namely, to, from, date, and subject-line: } \\
\text { E-em 14: } \\
\text { From: m } \\
\text { To: Journal of East Asian Linguistics } \\
\text { Sent: Saturday, February 17, 2007 10:10 PM } \\
\text { Subject: submission of an article }\end{array}$ \\
\hline b) Opening & $\begin{array}{l}\text { - It is taken as the conventional complimentary greeting observed at the beginning of some electronic } \\
\text { messages: } \\
\text { M-em 4: Dear Professor B }\end{array}$ \\
\hline Establishing the territory & - the writer provides sufficient background knowledge to trigger the addressee's relevant schemata \\
\hline a) Initial thanking & $\begin{array}{l}\text { - the writer refers to previous message in order to provide the addressee with some context: } \\
\text { M-em 13: Thank you very much for the previous communications }\end{array}$ \\
\hline $\begin{array}{l}\text { b) Expressing personal pleasure for } \\
\text { submission }\end{array}$ & $\begin{array}{l}\text { - the writer tries to express his /her enthusiasm and pleasure to submit an article to the journal } \\
\text { M-em 27: ... It is a pleasure for me to submit the attached paper... }\end{array}$ \\
\hline Providing information and answers & - It provides answers and information which may either be new or shared by both counterparts (Santos, 2002) \\
\hline a) Advising about message by mail & $\begin{array}{l}\text {-the writer lists documents attached to the electronic message or sends requested addresses or documents of } \\
\text { introducing the topic: } \\
\text { E-em 20: ...,please find our article... }\end{array}$ \\
\hline b-1) Indicating co-authorship & $\begin{array}{l}\text { - the writer refers to the submitted article as a shared authorship: } \\
\text { M-em } 18: \ldots \text { files of my joint paper... }\end{array}$ \\
\hline b-2) Providing author(s)' names & - M-em 22: ... joitly written with Professor "L. H"... \\
\hline $\begin{array}{l}\text { b-3) Providing article's number of } \\
\text { pages }\end{array}$ & - M-em 23: .... a survey article in 10 pages... \\
\hline b-4) Providing article title & - E-em 20: ... our article entitled " An Account of Null-Pre... \\
\hline
\end{tabular}




\begin{tabular}{|c|c|}
\hline b-5) Indicating file format & $\begin{array}{l}\text { - the writer indicates the electronic format by which the file was produced: } \\
\text { M-em 17: ... are LaTeX files of my new joint paper... }\end{array}$ \\
\hline Continuing, adding, or updating & $\begin{array}{l}\text { - The writer either supports his/her ideas or provides more contexts: } \\
\text { E-em 10: ..., plus my bio... } \\
\text { M-em 28: ....The manuscript has been prepared using... }\end{array}$ \\
\hline $\begin{array}{l}\text { Requesting information, action, and } \\
\text { favors }\end{array}$ & - the writer raises an issue or requests an action or a favor to be done \\
\hline a) Requesting for action & $\begin{array}{l}\text { - the writer states the specific action that he wants the reader to take: } \\
\text { E-em 19: ... for consideration and possible publication... }\end{array}$ \\
\hline a-1) Indicating journal name & - E-em 25: ... for publication in the Journal of Translation Studies... \\
\hline a-2) Indicating journal status & $\begin{array}{l}\text { - the writer, using descriptive adjectives, refers to the status and the quality of the publishing journal: } \\
\text { E-em } 22: . . \text { submit this article to your high caliber journal... }\end{array}$ \\
\hline $\begin{array}{l}\text { a-3) Referring to journals' } \\
\text { forthcoming issues }\end{array}$ & $\begin{array}{l}\text { - Wishing his/her article to be published forthcoming issues early-on, the writer refers to the journals' } \\
\text { upcoming issue as the one in which his/her article may be published. }\end{array}$ \\
\hline $\begin{array}{l}\text { b) Requesting for opinion, comments, } \\
\text { or suggestions }\end{array}$ & $\begin{array}{l}\text { - the writer requests for the addressees' suggestions opinion, comments, or suggestions on an unclear issue } \\
\text { using modals followed by please: } \\
\text { E-em 14: ... would you please kindly let me know if... }\end{array}$ \\
\hline $\begin{array}{l}\text { c) Indicating wishes, intentions, or } \\
\text { plans }\end{array}$ & - E-em 12: ... I hope you may find it suitable for publication... \\
\hline $\begin{array}{l}\text { d) Acknowledging receipt of a } \\
\text { message }\end{array}$ & $\begin{array}{l}\text { - the writer expresses his/her desire to be notified of the receipt of the article and the attachments: } \\
\text { E-em 28: ...Acknowledgement of the receipt of this mail ... }\end{array}$ \\
\hline e) Applying pressure tactics & $\begin{array}{l}\text { - Using a positive politeness strategy, the writer puts his /her addressee under pressure to respond to the } \\
\text { requests as he/she desires: } \\
\text { M-em 7: ... Please inform me about ......as soon as possible. }\end{array}$ \\
\hline Evaluating & $\begin{array}{l}\text { - the writer expresses his/her emotional feelings and intentions through appraising the issue of the concern } \\
\text { and expressing his/her opinion }\end{array}$ \\
\hline a) Giving personal opinion & $\begin{array}{l}\text { - Using certain lexical options that carry the meaning of personal impact, the writer presents his personal } \\
\text { opinion: E-em 25: ... which I think might be suitable for publication in the Journal of... }\end{array}$ \\
\hline b) Making comment & $\begin{array}{l}\text { - However indirectly, the writer may try to exert some degree of personal impact } \\
\text { E-em 22:... The quality of the articles published so far is excellent... }\end{array}$ \\
\hline Closing & - The participants sign off and provide individual professional data \\
\hline a) Encouraging further response & - M-em 26: ... I'm looking for hearing from you... \\
\hline b) Final thanking & $\begin{array}{l}\text { - Using complimentary phrases, the writer expresses thanks towards the addressee: } \\
\text { E-em 3: ... Many thanks in advance... }\end{array}$ \\
\hline c) Note and PS-line & $\begin{array}{l}\text { - The writer uses this step either to provide last-minute information or to convey relevant information that } \\
\text { deserves special attention (Santos, 2002): } \\
\text { E-em 21: P.S. I have enclosed my CV as well }\end{array}$ \\
\hline d) Signing off & $\begin{array}{l}\text { - the writer uses complementary phrases thus claiming the ownership of the message: } \\
\text { M-em 21: Truly Yours }\end{array}$ \\
\hline e) Signature line & $\begin{array}{l}\text { - the writer adds a signature line at the end of the message introducing him/herself by typing his/her 'name': } \\
\text { E-em 22: } \\
\text { Sincerely Yours } \\
\text { R. S }\end{array}$ \\
\hline f) Indicating job-status at university & $\begin{array}{l}\text { - the writer refers to his / her rank-status among the university academics where he /she teaches: } \\
\text { E-em 21: } \\
\text { R. S. PhD } \\
\text { Assistant Professor in Applied Linguistics }\end{array}$ \\
\hline g) Indicating university credentials & $\begin{array}{l}\text { - the writer provides information such as contact information and the exact whereabouts of the university he / } \\
\text { she is currently affiliated with } \\
\text { M-em } 25 \text { : } \\
\text { Department of pure math, Faculty of Mathematical sciences. } \\
\text { Tabriz university. } \\
\text { Tabriz, Iran }\end{array}$ \\
\hline h) Providing contact information & $\begin{array}{l}\text { - the writer provides his/ her own contact information for any potential communication } \\
\text { E-em 15: I can be contacted through the } \\
\text { following: } \\
\text { Mailing address } \\
\text { Iran, Tehran, P. O. Box: } 114 . .-1 . . \\
\text { e-mail address } \\
\text { m@cha...ut.a.... }\end{array}$ \\
\hline
\end{tabular}


Table 4. Frequency and Chi Square Results for Tense Types and Voice

\begin{tabular}{|c|c|c|c|c|c|}
\hline \multirow{2}{*}{\multicolumn{2}{|c|}{ Tense types and Voice }} & \multicolumn{2}{|c|}{ Frequency } & \multirow[t]{2}{*}{$\mathrm{x}^{2}$} & \multirow[t]{2}{*}{ P-value } \\
\hline & & EP & MP & & \\
\hline & Past & 3 & 1 & 1.000 & .317 \\
\hline \multirow[t]{2}{*}{ Tense } & Present & 74 & 44 & 7.627 & .006 \\
\hline & Active & 70 & 40 & 8.182 & .004 \\
\hline Voice & Passive & 46 & 57 & 1.755 & .278 \\
\hline \multicolumn{2}{|c|}{ Modals(should, could, and would) } & 19 & 36 & 5.255 & .022 \\
\hline
\end{tabular}

Table 5. Frequency and Chi-square Results for Personal Pronouns

\begin{tabular}{|c|c|c|c|c|}
\hline \multirow[t]{2}{*}{ Personal pronouns } & \multicolumn{2}{|c|}{ Frequency } & \multirow[t]{2}{*}{$x^{2}$} & \multirow[t]{2}{*}{ P-value } \\
\hline & EP & MP & & \\
\hline I & 31 & 25 & .643 & .423 \\
\hline You & 22 & 35 & 2.965 & .085 \\
\hline It & 10 & 7 & .529 & .467 \\
\hline S/he & 0 & 0 & - & - \\
\hline $\mathrm{We}$ & 5 & 0 & 2.667 & .102 \\
\hline They & 0 & 0 & - & - \\
\hline One/anyone & 0 & 0 & - & - \\
\hline
\end{tabular}

Table 6. Frequency and Chi-square Results for Different Forms Realizing the Opening Step

\begin{tabular}{|c|c|c|c|c|}
\hline \multirow[t]{2}{*}{ Different forms of opening } & \multicolumn{2}{|c|}{ Frequency } & \multirow[t]{2}{*}{$x^{2}$} & \multirow[t]{2}{*}{$P$-value } \\
\hline & EP & MP & & \\
\hline Dear + title + surname & 9 & 7 & .529 & .467 \\
\hline Dear + group(e.g., colleagues, all) & 2 & 1 & .333 & .564 \\
\hline Recipient's name & 0 & 0 & - & - \\
\hline Hello (all) & 0 & 0 & - & - \\
\hline Dear + editor & 8 & 3 & 1.395 & .238 \\
\hline Dear + journal name + editor & 2 & 0 & .194 & .659 \\
\hline Dear Sir/ Madam & 6 & 3 & 1.000 & .317 \\
\hline Dear + editor of + journal name & 1 & 1 & .000 & 1.000 \\
\hline Dear + title + first name + surname & 4 & 13 & 4.000 & .046 \\
\hline Respectful editor & 0 & 1 & .384 & .555 \\
\hline Dear editor-in-chief & 0 & 1 & .384 & .555 \\
\hline Messages without this step & 0 & 1 & .384 & .555 \\
\hline
\end{tabular}

Table 7. Frequency and Chi-square Results for Different Forms Realizing the Closing Step

\begin{tabular}{|c|c|c|c|c|}
\hline \multirow[t]{2}{*}{ Different forms of signing off politely } & \multicolumn{2}{|c|}{ Frequency } & $x^{2}$ & P-value \\
\hline & EP & MP & & \\
\hline (Best) (kind) regards & 12 & 5 & 4.000 & .046 \\
\hline (Yours) sincerely & 8 & 21 & 6.533 & .011 \\
\hline (All the) best (wishes) & 5 & 0 & 2.667 & .102 \\
\hline Sorry & 0 & 0 & - & - \\
\hline Cheers & 0 & 0 & - & - \\
\hline (Yours ) truly & 1 & 2 & .333 & .564 \\
\hline Respects & 1 & 0 & .384 & .555 \\
\hline (With) (the best) regards & 0 & 1 & .384 & .555 \\
\hline Yours & 1 & 0 & .384 & .555 \\
\hline E-mail messages with no ending & 2 & 2 & .000 & 1.000 \\
\hline
\end{tabular}

Table 8. Conversational Features Characteristic of Letters of Article Submission

\begin{tabular}{ll}
\hline Conversational feature & \\
\hline Discourse particles & - Typically found in spoken discourse, they are rare outside of the conversational genres (Biber, 1988): \\
& M-em13: Now,... \\
Abbreviations & - Their use may be seen as evidence for existence of specialized discourse communities (Swales, 1990) \\
& E-em 10: bio ...( conventionalized abbreviation, i.e., biography) \\
& E-em6: plz...(personalized abbreviations, i.e., please) \\
& - It is very rare in formal letters as it provides evidence for the stylistic similarity with informal spoken discourse \\
& (Gimenez 2000): \\
& E-em 7: ...by the time you've sent it... \\
& - Since decapitalization can be associated with informal unplanned discourse, capitalization is also worthy of some \\
Capitalization & consideration (Gimenez 2000): \\
& E-em 15: attached you will find... \\
\hline
\end{tabular}


Table 9. Frequency and Chi-square Results of Conversational Features

\begin{tabular}{|c|c|c|c|c|c|}
\hline \multicolumn{2}{|c|}{ Conversational features } & \multicolumn{2}{|c|}{ Frequency } & \multirow[t]{2}{*}{$\mathrm{x}^{2}$} & \multirow[t]{2}{*}{ P-value } \\
\hline & & $\mathrm{EP}$ & MP & & \\
\hline \multicolumn{2}{|c|}{ Discourse particles } & 0 & 2 & .194 & .659 \\
\hline \multirow[t]{2}{*}{ Abbreviation } & Standard & 7 & 13 & 1.800 & .180 \\
\hline & Non-standard & 4 & 0 & 3.000 & .083 \\
\hline \multicolumn{2}{|c|}{ Contracted forms } & 2 & 3 & .200 & .655 \\
\hline \multicolumn{2}{|c|}{ Decapitalization } & 8 & 1 & 5.444 & .020 \\
\hline
\end{tabular}

Table 10. Politeness Strategies Characteristic of Letters of Article Submission

\begin{tabular}{|c|c|}
\hline Politeness Strategy & Definition and exemplification \\
\hline Negative politeness strategies & $\begin{array}{l}\text { - They show that the speaker acknowledges the addressee's independence and freedom of } \\
\text { action (Brown and Levinson, 1987) }\end{array}$ \\
\hline a) Indirectness & $\begin{array}{l}\text { - The speaker uses linguistic structures that do not begin with words such as, I, you, or my } \\
\text { (Upton and Connor, 2001) } \\
\text { E-em 16: ... whether it fits the scope of your journal... }\end{array}$ \\
\hline b) Modals & $\begin{array}{l}\text { - Modals have the effect of softening them idea being communicated (Celce-Murcia \& } \\
\text { Larsen-Freeman, 1999): M-em 30: ... if you could let us know of the status of... }\end{array}$ \\
\hline c) Formulaic expressions & $\begin{array}{l}\text { - The intent of such expressions is to couch personal desires and wishes, and they are not in } \\
\text { themselves necessarily a negative politeness strategy (Upton and Conner, 2001): } \\
\text { E-em 3: ...I would appreciate it if you could kindly inform me of ... }\end{array}$ \\
\hline d) Expressing indebtedness & $\begin{array}{l}\text { - It is as 'going on record as incurring a debt' (Brown and Levinson (1987): } \\
\text { M-em 24:...I should be most grateful if... }\end{array}$ \\
\hline Positive politeness strategies & $\begin{array}{l}\text { - The speaker emphasizes shared goals and common ground of the addresser and addressee } \\
\text { (Upton and Conner, 2001) }\end{array}$ \\
\hline a) Directness & $\begin{array}{l}\text { - The writer threatens the independence of the addressee using sentences starting with the } \\
\text { phrase please }+ \text { action verb or the pronouns I, you, or my: } \\
\text { E-em 10: ... Please confirm the receipt of the email... }\end{array}$ \\
\hline
\end{tabular}

Table 11. Frequency and Chi-square Results of Negative Politeness Strategies

\begin{tabular}{|c|c|c|c|c|}
\hline \multirow[t]{2}{*}{ Negative politeness strategies } & \multicolumn{2}{|c|}{ Frequency } & $\mathrm{x}^{2}$ & P-value \\
\hline & EP & MP & & \\
\hline Indirectness & 10 & 11 & .048 & .827 \\
\hline Use of formulaic expressions & 3 & 12 & 5.400 & .020 \\
\hline Expressing indebtedness & 10 & 26 & 7.111 & .008 \\
\hline Modals & 19 & 36 & 5.255 & .022 \\
\hline
\end{tabular}

Table 12. Chi-square Results of Positive Politeness Strategies

\begin{tabular}{lccc}
\hline Positive politeness strategies & \multicolumn{2}{c}{ Frequency } & P-value \\
& EP & MP & \\
Please + action verbs & 12 & 22 & 2.941 \\
Using interrogatives & 0 & 0 & -086 \\
Directness & 31 & 31 &. \\
\hline
\end{tabular}

